\title{
PARENTAL ROLES AND THE AMOUNT OF CARE IN A BI-PARENTAL SUBSTRATE BROODING CICHLID: THE EFFECT OF SIZE DIFFERENCES WITHIN PAIRS
}

\author{
by
}

\begin{abstract}
SATOSHI AWATA and MASANORI KOHDA ${ }^{1,2)}$
(Laboratory of Animal Sociology, Department of Bio- and Geosciences, Graduate School of Science, Osaka City University, Sumiyoshi, Osaka 558-8585, Japan)
\end{abstract}

(Acc. 7-IX-2004)

\begin{abstract}
Summary
Parental roles and the amount of care in bi-parental fish have been assumed to be determined by sex. We studied the parental behaviour in a substrate brooding cichlid Julidochromis ornatus (40-90 $\mathrm{mm}$ in total length) in which both parents participate in care of eggs and young. In the study population, $c a 80 \%$ of paired females were larger than their partners and pairs mated assortatively for size. Males spent more time with their offspring in female-largest pairs, whereas the opposite was found for male-largest pairs. These differences in the amount of care were more conspicuous when differences in body size were greater, whereas similar sized pairs shared parental tasks. These results suggest that the amount of parental care is largely affected by the relative size within pairs independent of sex in J. ornatus. However, the frequencies of defensive behaviours were not different in both female-largest and malelargest pairs. This indicates that parental roles would not completely change as the change of the body size difference within pairs. The larger parents were socially dominant over the partners regardless of sex, and observations of aggressive behaviours within pairs suggest that the larger fish are likely to make the partners perform parental care. Higher frequencies of aggressive encounters were observed in the similar-sized pairs than in the different-sized ones. Higher costs associated with frequent aggressive behaviours in the similar-sized pairs may be related to their small brood size, and may be partly responsible for the size-assortative mating with sexual size difference in this fish.
\end{abstract}

\footnotetext{
1) Corresponding author's e-mail address: awata@sci.osaka-cu.ac.jp

2) We are grateful to the late Leonard M. Mwape, Reuben Shapola and the staff of Lake Tanganyika Research Unit for assistance in the field. We also wish to thank Murray Itzkowitz, Karen D. Crow and an anonymous referee for their helpful comments that greatly improved the manuscript. This research was financially supported by a Grant-in-Aid for overseas Scientific Research (No. 10041178) from Japanese Ministry of Education, Science, Sports and Culture.
} 
Keywords: parental care, sexual conflict, body size, size-assortative mating, substrate-brooding cichlid, Julidochromis ornatus.

\section{Introduction}

Bi-parental care is assumed to evolve in animals, where raising the offspring is likely to require both parents (Clutton-Brock, 1991a). In these animals, parental care is not always shared equally, and parental role specialization is found between males and females. For example, in many avian species, females are the principal caretakers spending more time incubating eggs, and males exclusively perform territory defence (Clutton-Brock, 1991b). However, few studies have examined how such differences in parental roles and the amount of care occur in bi-parental animals.

Although bi-parental care is rare in fishes, it is found in many cichlids and some catfishes (cichlids, reviewed by Keenleyside, 1991; Kuwamura, 1997; catfishes, Blumer, 1986; McKaye et al., 1994; Ochi et al., 2000, 2001). Among many of these fishes, females smaller than their mates are principal caretakers, which tend to remain with their offspring and perform direct care behaviours including fanning of eggs and cleaning of eggs and larvae. Males tend to be less close to their broods and mainly perform territory defence and/or brood defence against predators (Keenleyside \& Bietz, 1981; Itzkowitz, 1984; Kuwamura, 1986a; Nakano \& Nagoshi, 1990; Stiassny \& Gerstner, 1992). A reverse in these sex differences in parental roles has been reported for a Tanganyikan cichlid, Julidochromis marlieri (Yamagishi \& Kohda, 1996) and for a catfish Bagrus meridionalis (McKaye et al., 1994). In both species males are smaller than females. These examples suggest that the differences in size between males and females may play a role in sexual differences in parental roles and the amount of parental care in bi-parental fishes.

In some cichlids with predominantly bi-parental care, parental care patterns (i.e. the amount of care) sometimes change in relation to the changes in the relative costs and benefits to males and females. For example, operational sex-ratio (OSR) plays an important role in the care-patterns in the mouthbrooding cichlid Sarotherodon galilaeus; male or female desertion is more likely to occur when OSR is biased toward opposite sex (Balshine-Earn \& Earn, 1997, 1998). Similarly, male desertion under female-biased OSR has been reported for other bi-parental cichlids (e.g. Herotilapia multispinosa, 
Keenleyside, 1983; Cichlasoma panamense, Townshend \& Wootton, 1985). The care-patterns are also affected by the clutch size relative to the size of parents (Schwanck \& Rana, 1991; Balshine-Earn \& Earn, 1998). A recent study on the bi-parental cichlid Archocentrus nigrofasciatum by Itzkowitz et al. (2004) shows that the differences in size between males and females affect parental roles. They predict that, independent of sex, the larger parent is more likely to exhibit behaviours associated with defending the brood and the nest from intruders, while the smaller parent is more likely to remain in close proximity to offspring. These studies imply that the relative size within pairs is an important factor affecting parental roles in bi-parental fishes.

To test whether size differences affect variation in parental care between the sexes, we selected the species Julidochromis ornatus, which exhibits biparental care and variation in size differences between parents (e.g. one sex is smaller in some pairs but larger in others). We predict that independent of sex the smaller parent will be the principal caretaker, being more likely to stay with its offspring, and the larger mate is more likely to be engaged in territory and brood defence in J. ornatus (Itzkowitz et al., 2004). J. ornatus is one of the small substrate-brooding cichlids endemic to Lake Tanganyika (Kuwamura, 1997; Konings, 1998). They commonly breed in pairs, and both parents care for their eggs and young (Awata, unpubl. data). They are not sexually dimorphic with regard to colour patterns, morphology or body size. In the present paper, we describe the amount of parental care in J. ornatus in the wild and examine the relationships between parental roles or the amount of parental care and differences in size within pairs. Finally, we will discuss the advantages of larger (dominant) partners in parental roles with respect to relative size differences in mating pairs.

\section{Methods}

Subjects

Julidochromis ornatus inhabits rocky shores in the south and some parts of the north of Lake Tanganyika (Boulenger, 1898; Konings, 1998). This species forages primarily on benthic algae and sponges and sometimes on plankton (Hori, unpubl. data). Reproductively active fish of both sexes range from 40 to $90 \mathrm{~mm}$ in total length (TL). The sex ratio of sexually matured fish is not biased (Awata, unpubl. data). Monogamy is the most common tactic exhibited by this fish, although very large individuals of both sexes $(>80 \mathrm{~mm})$ often mate with multiple partners at different nests (polygamous harem) (Awata, unpubl. data). Helpers assisting brood care at the breeders' nests have been also found (Taborsky \& Limberger, 
1981; Awata, unpubl. data). Breeding pairs use rock crevices for breeding nests, providing shelter sites for both parents and young from predators. Eggs are laid on the inner side of rock crevice, and young are distributed on the substrate in and around the nests. Both parents guard their broods until the fry reach approximately $30 \mathrm{~mm}$ TL (approximately 3.5 months). Females spawn every two to four weeks, and different-sized young from different clutches are guarded together by parents in and around the nests.

\section{Field observations}

Field work was conducted from September to December 1998 and from August to November 1999 at Kasenga Point near Mpulungu at the southern end of Lake Tanganyika, Zambia, using SCUBA. Observation sites were different between the two years. Behavioural observations were made with 26 quadrat squares with $2 \mathrm{~m}$ sections $(2 \times 2 \mathrm{~m}-20 \times 30 \mathrm{~m})$. The quadrat squares were placed at a depth range of $3 \mathrm{~m}$ to $12 \mathrm{~m}$. A map of each square was drawn on waterproof paper on which behaviours and positions of the parental individuals were recorded during focal observations.

Individuals showed a high variation in body colour patterns and size that was used for individual recognition. In total 44 parental pairs were identified. At least one of the parents was present in or around the nest. For each parent a 15-min focal observation was conducted 3 to 4 times in the daytime (9:00-15:00 h) on different days. The following behaviours were recorded: (1) time spent in and around the nest (within $15 \mathrm{~cm}$ from the nest entrance), where parents effectively guard their offspring against potential predators, (2) swimming tracks, (3) frequency of attacks against unknown conspecifics and heterospecifics within $40 \mathrm{~cm}$ from the nest entrance, and (4) frequency of social interactions within pairs. The social interactions within pairs included attack, pecking (the parent opening its mouth and ramming into the body of its mate), threatening posture with open mouth, or appeasement with quivering body. Attack, pecking and threatening postures were regarded as intersexual aggressive behaviours. The reactions of partners after receiving aggressions were also recorded. To examine the motivation to stay close to their offspring, timing of fleeing behaviour due to the approach of an observer when both parents were at their nests were recorded once at 20 nests in 1999. Spawning events that might occur inside nests were not observed during this study.

After behavioural observations, 82 of 88 parental individuals (93\%) and 194 offspring (0-25 per nest) were captured with gillnets or with hand nets after application of the anaesthetic (30\% clove oil diluted in ethanol). We collected additional specimens of 17 pairs and 39 offspring (0-7 per nest) without behavioural observations. In the laboratory, total length (TL mm), standard length (SL mm), body wet weight (BW g), gonad wet weight (GW g) and sex were noted for each parental individual. The eviscerated condition factor $K$ was calculated as an index of individual physical condition, such that $K=(\mathrm{BW}-\mathrm{GW}) / \mathrm{SL}^{3} \times 10^{5}$.

\section{Data analysis}

At the study site, monogamy with bi-parental care was common $(N=43)$, and cooperative breeding with a small male-helper $(N=14)$ and a small female-helper was also observed $(N=4)$. In this study, we regarded them all as pairs regardless of the presence of the small helpers, because helpers spent the majority of their time in the nests and infrequently attacked heterospecifics. Therefore their presence did not seem to largely affect behaviour of the parents. Of 61 pairs, 17 pairs in which no behavioural observations were made were 
used for solely analyses of size and physical condition data, 6 were used for only analyses of behavioural data because of failures in collections of one parent, and the remaining 38 were used for all analyses.

As the direct parental care of eggs or young could not be observed, we used time spent in and around the nests and frequencies of attacks (including threats) against heterospecifics as indexes of parental care as in previous studies (e.g. Blumer, 1986; Keenleyside, 1991; Jennions \& Polakow, 2001). From analyses of parental care behaviours of fish in lab settings, we establish a positive relationship between time spent in the nest and the frequency of direct parental care: fanning and cleaning of the brood (Awata, unpubl. data). We compared the indexes of parental care as well as home-range sizes, frequencies of attacks against unknown conspecifics and frequencies of aggressive behaviours between males and females within pairs. In these comparisons, we divided the pairs into two groups: female-largest pairs (female $>$ male in size) and male-largest pairs. A brood usually contained several clutches, and new clutches had many small young (Awata, unpubl. data). To eliminate this bias in the examination of brood sizes, we used 18 broods that had fry over $20 \mathrm{~mm}$.

Statistical analyses were performed by using Stat View 5.0 (SAS Institute Inc., 1998). Non-parametric tests were used in analysing behavioural data and brood-size data because the data were not normally distributed and did not meet the assumptions for parametric tests. Parametric tests were used in analyses of size and physical condition data. All tests used were two-tailed.

\section{Results}

Of 55 pairs captured, 43 females were larger (female, $68.70 \mathrm{~mm} \pm 8.40 \mathrm{SD}$; male, $55.20 \pm 7.92$ ) and 12 males were larger than their mates (female, $54.71 \pm 11.71$; male, $66.15 \pm 9.31$ ). In either case, pairs mated assortatively for size (Fig. 1). In female-largest pairs and male-largest pairs, the size differences between sexes were $13.50 \mathrm{~mm} \pm 5.59 \mathrm{SD}$ (size ratio: large fish/small fish $=1.25 \pm 0.12 \mathrm{SD}$ ) and $11.44 \mathrm{~mm} \pm 4.67 \mathrm{SD}$ (size ratio: $1.22 \pm$ $0.10 \mathrm{SD})$, respectively. Pairs of similar body sizes were small in number (Fig. 1). The eviscerated condition factor $K$ of females was higher than that of males in female-largest pairs (female, $1.96 \pm 0.18 \mathrm{SD}$; male, $1.85 \pm 0.15$; paired $t$-test: $t=4.28, p=0.0001, N=43$ pairs), and a reversed tendency in the mean value between sexes seemed to be shown in male-largest pairs, although no significant difference was detected (female, $1.89 \pm 0.17$; male, $1.94 \pm 0.21 ; t=-0.89, p=0.39, N=12$ pairs) possibly because of small sample size.

In female-largest pairs, males spent more time in and around the nests and had smaller home ranges than their mates (Table 1). In male-largest pairs, on the contrary, males were away from the nests for a longer duration and had larger home ranges than their partners. Frequencies of attacks against 


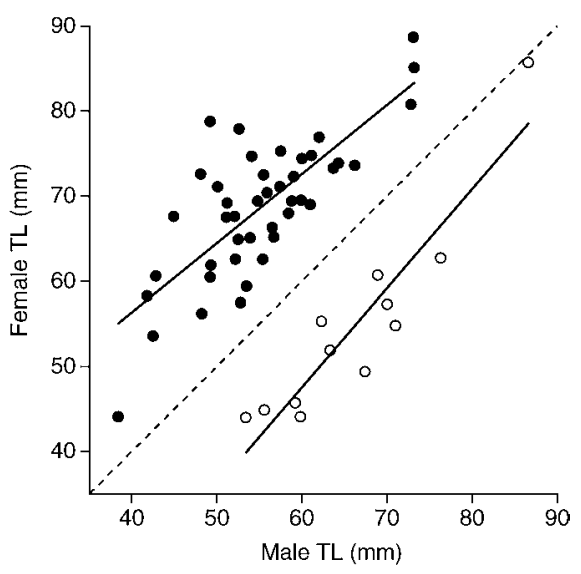

Fig. 1. Size relationship between male and female in breeding pairs. Female-largest pairs (solid circle, $N=43$ ) and male-largest pairs (open, $N=12$ ). A broken line is y $=\mathrm{x}$. Linear regression is given in solid circle $(\mathrm{y}=0.81 \mathrm{x}+23.82, r=0.77, p<0.0001)$ and open circle $(\mathrm{y}=1.16 \mathrm{x}-22.31, r=0.93, p<0.0001)$.

unknown conspecifics and heterospecifics were not significantly different between sexes in either type of pairs, but in female-largest pairs females were more likely to attack heterospecifics than males (Table 1).

Pairs with larger differences in body size showed larger differences in the time spent in and around the nests between sexes (Fig. 2a). When sex differences in size were small, both parents stayed in and around the nests in a similar degree. A significant positive correlation was found between the body size differences and the differences in home-range size within pairs (Fig. 2b).

When an observer approached pairs at their nests, larger individuals (14 females and two males) left their nests earlier than smaller ones in 16 of 20 cases $(80 \%)$. In the remaining four pairs (three female-largest and one male-largest pairs), both parents left $(N=1)$, or entered their nests $(N=3)$ at the same time.

Of a total of 196 intersexual aggressive behaviours observed in 22 of 37 female-largest pairs and 7 of 8 male-largest pairs, 151 (77\%) were performed by larger partners: 128 by 22 larger females and 23 by 6 larger males. The larger individuals more frequently performed aggressions toward the mates than their mates (Wilcoxon signed-ranks test; $T=19.50, p<0.0001$, $N=44$ pairs). We observed behaviours of parents after aggressions within pairs in 182 of 196 cases. One hundred and fifty-one aggressions occurred 


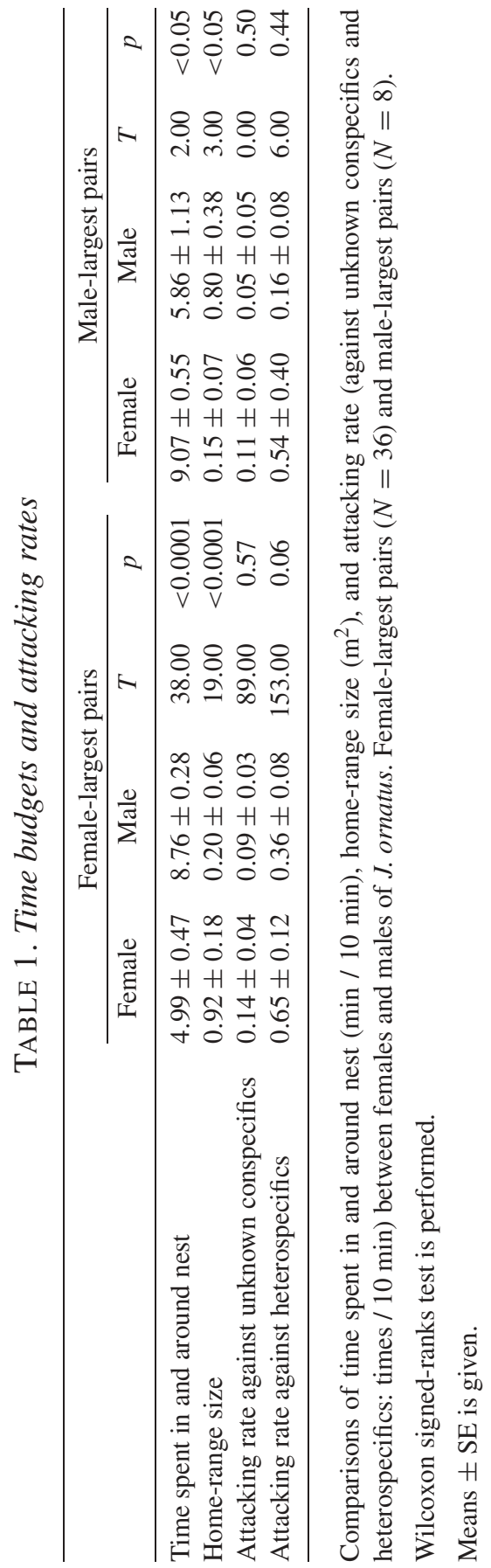




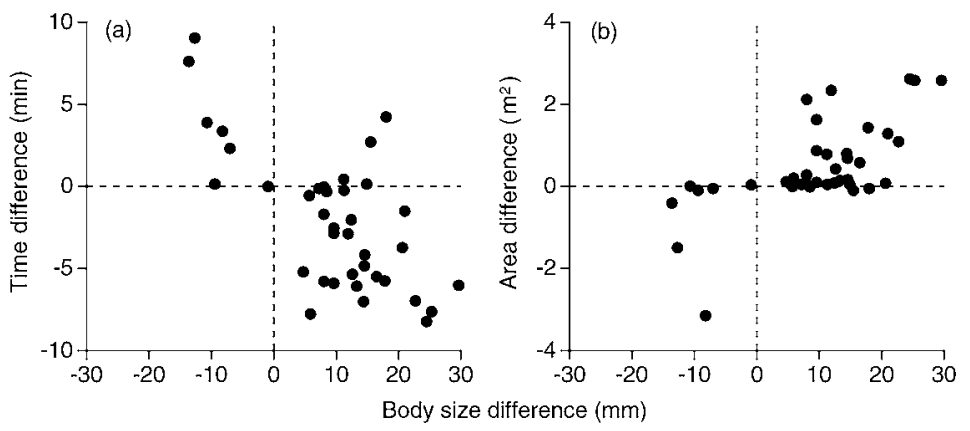

Fig. 2. Relationships between body size difference and (a) difference in time spent in and around nests (time difference) and (b) difference in home-range size (area difference) within pairs. All differences are given by (female-male) (Kendall's rank correlation; (a) $\tau=-0.42$,

$$
p=0.0002, N=38 \text { and (b) } \tau=0.46, p<0.0001, N=38 \text { ). }
$$

at the nest entrance or around the nests, and attacked fish got into the inner part of nests in most cases. In the remaining 33 cases, aggressions occurred at larger distance from their brood (large fish attacked in 31 of 33 cases), and attacked partners swam back into the nests soon after the aggressions. These partners were rarely attacked by their mates when they were close to their young. Although we did not record, smaller parents at the nest entrance or outside the nests occasionally got into the nests when the larger parents approached them. The total frequency of aggressions within pairs increased with decreasing the body size differences between sexes (Fig. 3a). The larger individuals attacked the mates more frequently when their body size differences were smaller (Fig. 3b). This tendency was found in aggressions of smaller individuals, although a significant correlation was not detected (Fig. 3c).

There was no significant correlation between female TL and brood size (Kendall's rank correlation; $\tau=-0.13, p=0.46, N=18$ pairs) and no significant difference in brood size between female-largest pairs (2.54 \pm $0.70 \mathrm{SE}$, range $=1-9, N=13)$ and male-largest pairs $(3.20 \pm 0.37 \mathrm{SE}$, range $=2-4, N=5$ ) (Mann-Whitney $U$-test; $U=18.50, p=0.15$ ). Thus, we pooled the data of brood size from both types of pairs, and divided the pairs into three classes according to the degree of size differences within pairs (Fig. 4). There was a significant difference in brood size among the three classes (Kruskal-Wallis test; $H=8.13, p=0.02$ ). Multiple comparisons (Mann-Whitney $U$-test employing Bonferroni adjustment; Rice, 1989) showed that the brood sizes in the middle class were significantly larger than 

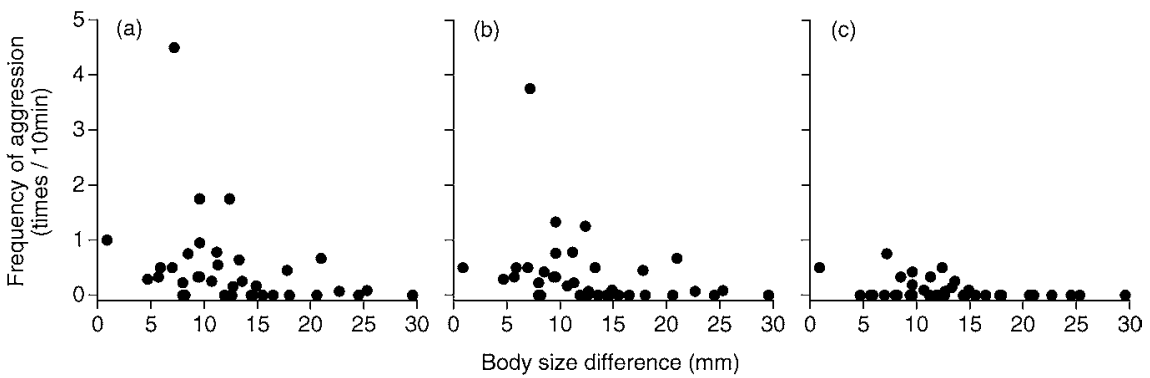

Fig. 3. Relationship between body size difference (large fish TL - small fish TL) and frequency of aggression within breeding pairs $(N=38)$. (a) The total frequency of aggression within pairs (Kendall's rank correlation; $\tau=-0.31, p=0.006$ ), (b) the frequency of larger individual aggression toward smaller mate $(\tau=-0.28, p=0.007)$, and (c) the frequency of smaller individual aggression toward larger mate $(\tau=-0.20, p=0.07)$.

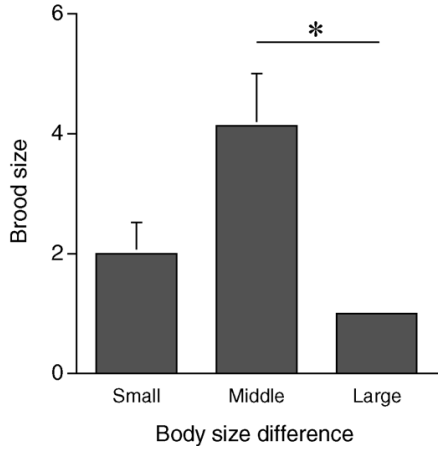

Fig. 4. Comparison of brood size among three classes divided by the body size difference between males and females (large fish TL - small fish TL). Small: up to $8 \mathrm{~mm}, N=5$, Middle: 8-16 mm, $N=8$, Large: $16-24 \mathrm{~mm}, N=4$. Vertical lines show standard errors. $* p<0.05$.

in the large class. Although a significant difference was not detected, the brood sizes in the middle class were likely to be larger than in the small class.

\section{Discussion}

The two-year field study on the parental behaviour of the bi-parental cichlid Julidochromis ornatus demonstrated that, independent of sex, the smaller partner within a pair showed most parental care. This higher parental ef- 
fort was expressed as spending more time to close to the brood. However, defensive behaviours (attacking rate against unknown conspecifics and heterospecifics) were not different between sexes, although in female-largest pairs females were likely to attack heterospecifics more frequently than males. This indicates that parental division of labour may exist but seems not to be strong in comparison with other bi-parental cichlids (e.g. Keenleyside \& Bietz, 1981; Itzkowitz, 1984). Also this indicates that parental roles of J. ornatus would not clearly change as the relative size within pairs. These results partly support the hypothesis by Itzkowitz et al. (2004) and our prediction that, irrespective of sex in bi-parental care fish, larger parents are more likely to attack the intruders, and smaller mates are principal caretakers being more likely to stay close to their offspring.

In some cichlids with predominantly bi-parental care, the differences in the amount of parental care between sexes are affected by OSR (e.g. Keenleyside, 1983; Townshend \& Wootton, 1985; Balshine-Earn \& Earn, 1997, 1998). In the studied population a stable equal sex-ratio existed in sexually matured fish (Awata, unpubl. data), and intra-pair variation in the amount of care could thus not be attributed to differences in OSR. Clutch sizes and the size of buccal cavities of both parents relative to clutch sizes also affect care-patterns (i.e. the amount of care) in the mouth-brooding cichlid S. galilaeus (Schwanck \& Rana, 1991; Balshine-Earn \& Earn, 1998). J. ornatus is not a mouth-brooder, and clutch sizes of J. ornatus are very small (10-30 eggs per clutch, Konings, 1998; Awata, unpubl. data) and not highly variable with female sizes compared to S. galilaeus (200->1000 eggs per clutch, Schwanck \& Rana, 1991; Balshine-Earn, 1996). Thus, the clutch sizes are unlikely to be responsible for the intra-pair variation in the amount of care.

Sex specific parental roles have been reported for many bi-parental fishes (e.g. Keenleyside, 1991; Kuwamura, 1997). In most substrate brooding cichlids, principal caretakers are females that are smaller than male mates (e.g. Keenleyside \& Bietz, 1981; Itzkowitz, 1984). By contrast, in some species small males perform more offspring care and large female mates more territory defence (cichlid, Yamagishi \& Kohda, 1996; catfish, McKaye et al., 1994; clownfish, Yanagisawa \& Ochi, 1986). This tendency is also known in bi-parental birds. In many avian species, females that are smaller than their mates usually provide higher levels of parental care than males, e.g. relatively more time incubating eggs (Clutton-Brock, 1991b). However, in 
some bi-parental birds parental roles are reversed, males showing higher levels of parental care than females (spotted sandpiper, Maxson \& Oring, 1980; Eurasian dotteral, Kålås \& Byrkjedal, 1984; killdeer, Brunton, 1988; little spotted kiwi, Jolly, 1989). In these cases males are smaller than females (Jehl \& Murray, 1986; Clutton-Brock, 1991b). Our findings may correspond with these tendencies seen in the comparisons among cichlids and birds. Thus, in bi-parental species size differences might affect the sexual variation in parental care. In J. ornatus the difference in the amount of parental care between sexes was more conspicuous when the size difference became larger. This relationship between size difference and parental care resembles the comparative study among shore birds by Reynolds \& Székely (1997) showing that the duration of care by either sex decreases as increasing the relative size of the sex to the other.

At the approach of an observer, larger individuals of J. ornatus fled sooner than smaller breeding mates regardless of sex. Among bi-parental fishes and birds, mate and brood desertion by females that care for the brood more than males, is less frequent than by males (Keenleyside, 1983, 1991; Amat et al., 2000). However, desertion by females being larger than their mates has been found in some fishes and birds, in which small males provide more parental care than females (fishes, McKaye et al., 1994; Yamagishi \& Kohda, 1996; birds, Kålås \& Byrkjedal, 1984; Brunton, 1988). Thus, similar to other bi-parental animals, independent of sex, larger mates of J. ornatus showing relatively lowest levels of parental care have the prerogative of mate desertion.

In J. ornatus, males mated with females assortatively for size, which has been documented in many bi-parental cichlids with an extended pair-bond (male > female, e.g. McKaye, 1986; Yanagisawa, 1986; Wisenden, 1995; Morley \& Balshine, 2002; female > male, Yamagishi \& Kohda, 1996). To our knowledge, however, the strong assortative-mating by size in both two types (male $>$ female and female $>$ male) within a population as found in $J$. ornatus has not been previously reported. Size-dependent mate choice by either or both sexes and associated intrasexual competition may be the major force producing size-assortative mating (e.g. McKaye, 1986; Crespi, 1989; Rahman et al., 2002). This may be the case for J. ornatus, showing high fecundity of large females and predominance in intrasexual competition of large individuals of both sexes (Awata, unpubl. data). 
In both types of pairs, there were size differences between the sexes. Intrapair aggression was mostly followed by the smaller partner to swim back to the nest, indicating that the larger partner might make its partner perform parental care. Even when the larger parents approached their mates at the nest entrance, similar effects were occasionally detected. In addition, the larger fish had better physical condition than the smaller mates, indicating that the cost of parental care to smaller parents is higher, and sexual conflict over parental care may occur. The total frequency of aggressions within pairs increased when their size differences were small. In such pairs the larger parent might have difficulty in controlling the smaller mate over parental care, and subsequently the frequency of aggressive behaviours increased. The pairs being well matched for the size differences $(8-16 \mathrm{~mm})$ tended to have larger brood sizes than those of other size combinations. The small size differences within pairs seem to impose the costs on both parents associated with the frequent aggressions (and probably the lower brood sizes), as in the clownfish where members of reproductive units are organized by the dominance hierarchy associated with well-defined size differences among individuals (Buston, 2003). This disadvantage in similar sized pairs may induce assortative mating by size with optimal size differences between sexes in J. ornatus.

Within the studied population, females of J. ornatus were typically larger than their mates, whereas in a minority the sizes reversed. Why were both types of pairs found? Two factors which are unique in social and reproductive features in J. ornatus may be relevant to this question. First, although they show bi-parental care, the cost of parental care is likely to be lower than other bi-parental cichlids; J. ornatus breed in rock crevices, and their fry is the benthic type, which is considered to be more easily defended by parents from fry predators than the vertical type distribution of fry (Kuwamura, 1986b; Yanagisawa, 1987; Gashagaza, 1991). Second, the large fish of both sexes (>80 mm TL) often becomes the harem master and may obtain greater reproductive success thereafter (Awata, unpubl. data). Under the situation that the cost of parental care is lower and that one parent can obtain other breeding chances, the parent will compel its partner to perform parental care. Therefore, in J. ornatus, independent of sex, the larger (dominant) partner may reduce the amount of parental care and have a large home range for a chance of additional mating. 
In conclusion, J. ornatus forms a pair with a size-matched but a differentsized partner, and the smaller parents of either sex take responsibility for major parental duties. This bias seems to be induced by sexual conflict over parental care and additional mating, where the larger parents are dominant and might have an advantage for their future reproduction.

\section{References}

Amat, J.A., Visser, G.H., Pérez-Hurtado, A. \& Arroyo, G.M. (2000). Brood desertion by female shorebirds: a test of the differential parental capacity hypothesis on Kentish plovers. - Proc. R. Soc. Lond. B 267, p. 2171-2176.

Balshine-Earn, S. (1996). Reproductive rates, operational sex ratios and mate choice in St. Peter's fish. - Behav. Ecol. Sociobiol. 39, p. 107-116.

— — \& Earn, D.J.D. (1997). An evolutionary model of parental care in St. Peter's fish. — J. theor. Biol. 184, p. 423-431.

- — \& - (1998). On the evolutionary pathway of parental care in mouth-brooding cichlid fish. - Proc. R. Soc. Lond. B 265, p. 2217-2222.

Blumer, L.S. (1986). Parental care sex differences in the brown bullhead, Ictalurus nebulosus (Pisces, Ictaluridae). - Behav. Ecol. Sociobiol. 19, p. 97-104.

Boulenger, G.A. (1898). Report on the collection of fishes made by Mr. J.E.S. Moore in Lake Tanganyika during his expedition, 1895-96. - Trans. Zool. Soc. Lond. 15, p. 1-30.

Brunton, D.H. (1988). Sexual differences in reproductive effort: time-activity budgets of monogamous killdeer, Charadrius vociferus. - Anim. Behav. 36, p. 705-717.

Buston, P. (2003). Size and growth modification in clownfish. - Nature 424, p. 145-146.

Clutton-Brock, T.H. (1991a). The evolution of parental care. - Princeton Univ. Press, Princeton, New Jersey.

- - (1991b). Parental care in birds and mammals. — In: The evolution of parental care (T.H. Clutton-Brock, ed.). Princeton Univ. Press, Princeton, New Jersey, p. 130-152.

Crespi, B.J. (1989). Causes of assortative mating in arthropods. - Anim. Behav. 38, p. 9801000.

Gashagaza, M.M. (1991). Diversity of breeding habits in Lamprologine cichlids in Lake Tanganyika. — Physiol. Ecol. Japan 28, p. 29-65.

Itzkowitz, M. (1984). Parental division of labor in a monogamous fish. - Behaviour 89, p. 251-260.

_ - , Santangelo, N., Cleveland, A., Bockelman, A. \& Richter, M. (2004). Is the selection of sex-typical parental roles based on an assessment process? A test in the monogamous convict cichlid fish. - Anim. Behav. (in press).

Jehl, J.R., Jr. \& Murray, B.G., Jr. (1986). The evolution of normal and reverse sexual size dimorphism in shorebirds and other birds. - In: Current Ornithology, Vol. 3 (R.F. Johnston, ed.). Premium Press, New York, p. 1-86.

Jennions, M.D. \& Polakow, D.A. (2001). The effect of partial brood loss on male desertion in a cichlid fish: an experimental test. - Behav. Ecol. 12, p. 84-92.

Jolly, J.N. (1989). A field study of the breeding biology of the little spotted kiwi (Apteryx owenii) with emphasis on the causes of nest failures. - J. Roy. Soc. New Zealand 19, p. 433-448. 
Kålås, J.A. \& Byrkjedal, I. (1984). Breeding chronology and mating system of the Eurasian dotterel (Charadrius morinellus). - Auk 101, p. 838-847.

Keenleyside, M.H.A. (1983). Mate desertion in relation to adult sex ratio in the biparental cichlid fish Herotilapia multispinosa. - Anim. Behav. 31, p. 683-688.

— — (1991). Parental care. — In: Cichlid fishes: behaviour, ecology and evolution (M.H.A. Keenleyside, ed.). Chapman \& Hall, London, p. 191-208.

— — \& Bietz, B.F. (1981). The reproductive behaviour of Aequidens vittatus (Pisces, Cichlidae) in Surinam, South America. — Environ. Biol. Fish. 6. p. 87-94.

Konings, A. (1998). Tanganyika cichlids in their natural habitat. — Cichlid Press.

Kuwamura, T. (1986a). Substratum spawning and biparental guarding of the Tanganyikan cichlid Boulengerochromis microlepis, with notes on its life history. - Physiol. Ecol. Japan 23, p. 31-43.

_ - (1986b). Parental care and mating systems of cichlid fishes in Lake Tanganyika: a preliminary field survey. - J. Ethol. 4, p. 129-146.

- - (1997). The evolution of parental care and mating systems among Tanganyikan cichlids. — In: Fish communities in Lake Tanganyika (H. Kawanabe, M. Hori \& M. Nagoshi, eds.). Kyoto University Press, Kyoto, p. 57-86.

Maxson, S.J. \& Oring, L.W. (1980). Breeding season time and energy budgets of the polyandrous spotted sandpiper. - Behaviour 74, p. 200-263.

McKaye, K.R. (1986). Mate choice and size assortative pairing by the cichlid fishes of Lake Jiloá, Nicaragua. — J. Fish Biol. 29. p. 135-150.

— - Mughogho, D.E. \& Stauffer, J.R., Jr. (1994). Sex-role differentiation in feeding and defence of young by a biparental catfish, Bagrus meridionalis. - Anim. Behav. 48, p. 587-596.

Morley, J.I. \& Balshine, S. (2002). Faithful fish: territory and mate defence favour monogamy in an African cichlid fish. - Behav. Ecol. Sociobiol. 52, p. 326-331.

Nakano, S. \& Nagoshi, M. (1990). Brood defence and parental roles in a biparental cichlid fish Lamprologus toae in lake Tanganyika. — Japan. J. Ichthyol. 36, p. 468-476.

Ochi, H., Rossiter, A. \& Yanagisawa, Y. (2000). The first record of a biparental mouthbrooding catfish. - J. Fish Biol. 57, p. 1601-1604.

- _ - _ — \& - (2001). Biparental mouthbrooding of the catfish Phyllonemus filinemus in Lake Tanganyika. - Ichthyol. Res. 48, p. 225-229.

Rahman, N., Dunham, D.W. \& Govind, C.K. (2002). Size-assortative pairing in the bigclawed snapping shrimp, Alpheus heterochelis. - Behaviour 139, p. 1443-1468.

Reynolds, J.D. \& Székely, T. (1997). The evolution of parental care in shorebirds: life histories, ecology, and sexual selection. - Behav. Ecol. 8, p. 126-134.

Rice, W.R. (1989). Analyzing tables of statistical tests. - Evolution 43, p. 223-225.

SAS Institute, Inc. (1998). Statview for Macintosh, Version 5.0. — Cary: SAS Institute Inc.

Schwanck, E. \& Rana, K. (1991). Male-female parental roles in Sarotherodon galilaeus (Pisces: Cichlidae). - Ethology 89, p. 229-243.

Stiassny, M.L.J. \& Gerstner, C.L. (1992). The parental care behaviour of Paratilapia polleni (Perciformes, Labroidei), a phylogenetically primitive cichlid from Madagascar, with a discussion of the evolution of maternal care in the family Cichlidae. - Environ. Biol. Fish. 34, p. 219-233.

Taborsky, M. \& Limberger, D. (1981). Helpers in fish. — Behav. Ecol. Sociobiol. 8, p. 143145. 
Townshend, T.J. \& Wootton, R.J. (1985). Variation in the mating system of a biparental cichlid fish, Cichlasoma panamense. - Behaviour 95. p. 181-197.

Wisenden, B.D. (1995). Reproductive behaviour of free-ranging convict cichlids, Cichlasoma nigrofasciatum. - Environ. Biol. Fish. 43, p. 121-134.

Yamagishi, S. \& Kohda, M. (1996). Is the cichlid fish Julidochromis marlieri polyandrous? — Ichthyol. Res. 43, p. 469-471.

Yanagisawa, Y. (1986). Parental care in a monogamous mouthbrooding cichlid Xenotilapia flavipinnis in Lake Tanganyika. — Japan. J. Ichthyol. 33, p. 249-261.

- - (1987). Social organization of a polygynous cichlid Lamprologus furcifer in Lake Tanganyika. - Japan. J. Ichthyol. 34, p. 82-90.

— — \& Ochi, H. (1986). Step-fathering in the anemonefish Amphiprion clarkii: a removal study. - Anim. Behav. 34, p. 1769-1780. 